\title{
The sleep-dream cycle and brain serotonin
}

ERNEST HARTMANN 1

TUFTS UNIVERSITY SCHOOL OF MEDICINE AND BOSTON STATE HOSPITAL

This report presents data from three experiments investigating the effects of agents which change brain serotonin levels upon the length of the sleep-dream cycle in the rat.

The sleep-dream cycle is probably one of the basic biological cycles of the mammalian body (Hartmann, 1967). The cycle is defined as the time from the end of one D-period (paradoxical sleep period) to the end of the next D-period during sleep; in other words, it includes one $\mathrm{D}$-period plus one $\mathrm{S}$ period (slow-wave sleep period) and at times a brief awake period. In the human adult, the cycle length is between 90 and $100 \mathrm{~min}$; we have found remarkably little intrasubject or intersubject variation. Although this $90-\mathrm{min}$ cycle is easily detectable only during sleep, there is some evidence that it may continue throughout the 24-h day (Hartmann, 1967; Richter, 1965; Globus, 1966). Each mammalian species has its characteristic cyclelength, and there is a clearcut inverse relationship between the basal metabolic rate of the species and the sleepdream cycle length (Hartmann, 1967): The larger mammals, with a low metabolic rate, slow pulse, long gestation period, and so on, also have a long sleepdream cycle.

There is evidence that the sleep-dream cycle may be under some form of neurohumoral control (Jouvet, 1962; Hartmann, 1966a), and we have suggested that serotonin may be involved (Hartmann, 1966b, 1967); the present study tests the effect on the cycle of three methods of altering brain serotonin levels in the rat: (1) administration of a tryptophane-free diet, which decreases brain serotonin levels (Boullin, 1963) (2) administration of excess 1-tryptophane, which increases brain serotonin (Hess, Redfield, \& Udenfriend, 1959); (3) adminstration of lysergic acid diethylamide (LSD) which increases brain serotonin and decreases brain norepinephrine levels (Freedman, 1961). Method

Ss for this study were six-month-old male Charles River rats, weighing about $500 \mathrm{~g}$ each. Stainless steel electrodes were implanted in a total of 20 animals; one electrode in the left posterior cortex, one in the left hippocampus, two electrodes implanted in the dorsal neck muscles, and one indifferent electrode embedded in the cement plug attached to the skull.

One month after operation, animals were first adapted to the laboratory, a semi-dark, sound-attenuated room. Each rat was studied for a number of 5-h recording periods, usually spaced three or four days apart; each recording period ran from $10 \mathrm{AM}$ to 3PM. The first three recording periods for each animal were used only to establish adaptation to the laboratory and check on legibility of the records. A number of animals were eliminated from further study since the records did not show sufficiently clear demarcations between waking, S (slow-wave sleep), and D (paradoxical sleep). Each rat finally used was studied for at least 15 5-h recordings over a two to three month period.

The tryptophane-free diet was supplied as a casein hydrolysate mixture which, we have demonstrated, produced a $40 \%$ decrease in brain serotonin levels over a period of four weeks in rats of this age. Seven rats were studied for at least five baseline recording periods each on a normal diet (in addition to adaptation recordings), and were then placed on the tryptophane-free diet for 30 days; four recording periods were obtained towards the end of the month on this diet, and at least two further recording periods were obtained a month after the rats had been returned to their normal diet.

A diet including excess 1-tryptophane, an additional $2.5 \mathrm{~g}$ per $100 \mathrm{~g}$ of diet, was administered to four animals. This provided about 36 times the usual tryptophane content. After control diet recordings, this diet was administered for one week, during which three 5-h recordings were obtained from each animal. From the animals' weights, it appears that they ate a normal amount, but it is impossible to give an exact figure for the tryptophane intake of each rat.

LSD-25 was administered on four occasions to each of two animals, in doses of 2.5, 3.75, 5.0, and 10.0 $\mu \mathrm{g} / \mathrm{kg}$; LSD was administered in distilled water by IP injection, $1 / 2 \mathrm{~h}$ before the $5-\mathrm{h}$ recording period. The LSD recordings were randomly distributed among eight placebo (distilled water injection) recordings.

Each rat was used as his own control; recording periods under the experimental conditions were compared with recording periods under control or placebo conditions in the same animal.

In all rats it was possible to differentiate clearly and easily from the electrographic records three basic states, Waking (W), Slow-wave sleep (S), and D. Waking was characterized by high muscle tone, low voltage fast activity in the cortex, and low voltage fast with some theta activity in the hippocampus; $S$ was characterized by a lower level of muscle potential, and high voltage slow waves in the cortex and hippocampus; D was characterized by a further decrease in muscle potential and extremely regular hippocampal theta activity. Each record was scored for W, S, and $D$ by a scorer blind to the treatment condition. Total sleep time (S plus D), total D-time, D-time percent of sleep, and mean cycle length were calculated. One cycle was defined as the time from the end of one $D$-period to the end of the next if $1 \mathrm{~min}$ or less of 
Table 1. The effect of three experimental conditions on sleep time, and D-time (per 5-h recording period) and on length of the sleep-dream cycle. Each number represents the mean value for the number of recording periods indicated.

\begin{tabular}{lcccc} 
& $\begin{array}{c}\text { Total } \\
\text { Sleep } \\
\text { (Min) }\end{array}$ & $\begin{array}{c}\text { Total } \\
\text { D } \\
\text { (Min) }\end{array}$ & $\begin{array}{c}\text { D-Percent } \\
\text { of Sleep }\end{array}$ & $\begin{array}{c}\text { Cycle } \\
\text { Length } \\
\text { (Min) }\end{array}$ \\
\hline $\begin{array}{l}\text { Experiment 1: } \\
\text { Normal Diet } \\
\text { (32 recording periods) }\end{array}$ & 212.8 & 26.9 & 12.6 & 8.8 \\
$\begin{array}{l}\text { Tryptophane-Free Diet } \\
\text { (36 recording periods) }\end{array}$ & 201.9 & 23.8 & 11.8 & $10.6 * *$ \\
$\begin{array}{l}\text { Experiment 2: } \\
\text { Normal Diet } \\
\text { (28 recording periods) }\end{array}$ & 181.3 & 20.4 & 11.3 & 10.3 \\
$\begin{array}{l}\text { Excess-Tryptophane Diet } \\
\text { (9 recording periods) }\end{array}$ & 166.0 & 16.8 & 10.1 & $7.5 *$ \\
$\begin{array}{l}\text { Experiment 3: } \\
\text { Control (Placebo) } \\
\text { (16 recording periods) }\end{array}$ & 165.2 & 16.8 & 10.1 & 11.1 \\
$\begin{array}{l}\text { LSD } \\
(8 \text { recording periods) }\end{array}$ & 165.4 & $25.0 * *$ & $15.1 * *$ & $9.3 * *$ \\
\hline
\end{tabular}

${ }^{*} p<.05, * * p<.01$ using the Mann-Whitney U-test and the Wilcoxon matched-pairs signed-ranks test.

waking was included; any cycles with more waking were excluded. A typical 5-h recording contained at least 10 complete cycles.

Results

Table 1 presents the results in terms of mean values for all animals for each treatment condition. Since different groups of animals were used for each experiment, the values for control recording periods are not identical in the three experiments.

None of the three experimental conditions had a significant effect on total sleep; both the tryptophanefree diet and the excess tryptophane diet produced a mild disturbance in sleep, associated with slightly less than normal total sleep time. Total D-time and D-time percent were increased by LSD but hardly affected by the two diets. This is in general agreement with a study of LSD in man (Muzio, Roffwarg, \& Kaufman, 1966), but not with a similar study in the cat (Hobson, 1964). Dosage differences may be very important here.

The sleep-dream cycle length was significantly changed in each of the three experimental conditions. The tryptophane-free diet was associated with an increase in cycle length. The excess tryptophane diet and LSD were associated with a decrease in cycle length. The magnitude of change was only about $20 \%$ in each instance, but the results represent mean values for a total of about 1100 cycles. There was considerable variation between animals in terms of total sleep and total D-time. However, the change in cycle length, in the direction indicated, occurred in every animal.
Clearly, each of the three experimental agents produced a number of effects other than changes in brain serotonin levels. For instance, both the tryptophanefree diet $^{2}$ and the excess tryptophane diet produced somewhat more agitation during waking, and a very slight increase in sleep disturbance measured by a number of awakenings during the 5-h recordings. It is possible that this non-specific disturbance had something to do with the slight decrease in D-time found in both situations, but it is unlikely that it was related to the change in cycle length, since the cycle length changed in opposite directions under these two conditions. The administration of LSD produces, in addition to the increase in brain serotonin levels, a fall in brain norepinephrine levels, and a number of other changes, which might be of importance.

However, in view of our difficulties in producing cycle length changes by a variety of other agents, the change in cycle length in the three experiments can probably most economically be explained on the basis of altered serotonin levels; increased brain serotonin levels appear to be associated with a shorter sleepdream cycle, and decreased levels with a longer cycle.

\section{References}

Boullin, D. Behavior of rats depleted of 5-hydroxytryptamine by feeding a diet free of tryptophan. Psychopharmacologia (Berlin), $1963,5,28-38$.

Freedman, D. The effect of LSD on brain serotonin. J. Pharmacol. exp. Ther., 1961, 134, 160-166.

Globus, G. Rapid eye movement cycle in real time. Arch. gen. Psychiat., 1966, 15, 654-659.

Hartmann, E. Mechanism underlying the sleep-dream cycle. Nature, $1966 \mathrm{a}, 212,648-650$.

Hartmann, E. Reserpine: Its effect on the sleep-dream cycle in man. Psychopharmacologia (Berlin), 1966b, 8, 242-247.

Hartmann, E. The biology of dreaming. Springfield, Illinois: Charles Thomas, 1967.

Hess, S., Redfield, B., \& Udenfriend, S. The effect of monoamine oxidase inhibitors and tryptophan on the tryptamine content of animal tissues and urine. J. Pharmacol. exp. Ther., 1959, 134, 178.

Hobson, J. The effect of LSD on sleep cycle in the cat. EEG clin. Neurophysiol., 1964, 17, 52-56.

Jouvet, M. Recherches sur les structures nerveuses et les mecanismes responsables des differentes phases du sommeil physiologique. Arch. Ital. Biol., 1962, 100, 125-206.

Muzio, J., Roffwarg, H., \& Kaufman, E. Alterations in the nocturnal sleep cycle resulting from LSD. EEG clin. Neurophysiol., $1966,21,313-324$.

Richter, D. Biological clocks in medicine and psychiatry. Springfield, Illinois: Charles Thomas, 1965.

\section{Notes}

1. Career Investigator, NIMH.

2. Results on the tryptophane-free diet were originally reported by E. Hartmann, D. Freedman, M. Zack, and R. Kluft to the Association for the Psychophysiological Study of Sleep, Gainesville, Florida, March 1966. 